\title{
Production of recombinant channel catfish (Ictalurus punctatus) FSH and LH in S2 Drosophila cell line and an indication of their different actions
}

\author{
Nilli Zmora, Yukinori Kazeto, R Sampath Kumar, Rüdiger W Schulz ${ }^{1,2}$ and John M Trant \\ Center of Marine Biotechnology, University of Maryland Biotechnology Institute, 701 East Pratt Street, Baltimore, Maryland 21202, USA \\ ${ }^{1}$ Research Group Endocrinology and Metabolism, Department Biology, Faculty of Sciences, University of Utrecht, Padualaan 8, $3584 \mathrm{CH}$ Utrecht, The \\ Netherlands \\ ${ }^{2}$ Physiology of Growth and Reproduction in Fish, Institute of Marine Research, PO Box 1870 Nordnes, 5817 Bergen, Norway \\ (Requests for offprints should be addressed to Y Kazeto who is now at Division of Marine Life Sciences Research, Faculty of Fisheries Science Hokkaido \\ University 3-1-1 Minato-cho Hakodate, Hokkaido 041-8611 Japan; Email: kazeto@fish.hokudai.al.jp) \\ (R S Kumar is now at Cellular and Molecular Sciences, Wyeth Biopharma, 1 Burtt Road, Andover, Massachusetts 01810, USA)
}

\begin{abstract}
Due to the lack of purified, native gonadotropins $(\mathrm{GtH})$ for almost all species of fish, we designed a system for the production of recombinant bioactive luteinizing hormone ( $\mathrm{LH})$ and follicle stimulating hormone (FSH) using the channel catfish (Ictalurus punctatus) as a model animal. The strategy was to produce the three subunits composing FSH and $\mathrm{LH}$, i.e. the common $\alpha$-subunit $(\alpha$-glycoprotein hormone $(\alpha-\mathrm{GP})), \beta-\mathrm{FSH}$, and $\beta-\mathrm{LH}$ subunit, individually in stable recombinant insect cells (S2) with C-terminal His-tag. This expression system was also used to co-express the $\alpha$-subunit without the His-tag with each of the His-tagged $\beta$-subunits. The recombinant S2 cells were capable of secreting FSH and LH heterodimers and $\alpha$-GP in abundance; however, expression of the individual $\beta$-subunits was much less successful. The recombinant GtHs were partially purified from the cell
\end{abstract}

medium by immobilized metal affinity chromatography to $\sim 15 \%$ purity with a yield of 7 and $4 \mathrm{mg}$ per liter of medium for FSH and $\mathrm{LH}$ respectively. These recombinant GtHs activated their receptors in vitro, enhanced estrogen secretion, up-regulated several steroidogenic enzyme genes in channel catfish ovarian follicles, and increased androgen secretion from African catfish testis. Interestingly, the FSH and LH dose-response curves for each of these biological activities clearly demonstrate differences in their cellular action and physiological roles. This expression system may be an important development for the production of speciesspecific GtHs so that FSH- and LH-specific mechanisms of actions within the reproductive endocrine processes can finally be examined with homologous, albeit recombinant, hormones.

Journal of Endocrinology (2007) 194, 407-416

\section{Introduction}

In fish, as in other vertebrates, gonadal steroidogenesis is controlled by the pituitary gonadotropins, follicle-stimulating hormone (FSH), and luteinizing hormone (LH; Gharib et al. 1990). FSH and LH belong to the glycoprotein hormone family, which consists of FSH, LH (and CG in certain mammals), and thyroid-stimulating hormone (TSH). They are all characterized by a heterodimeric structure, consisting of a common $\alpha$-subunit $(\alpha$-glycoprotein hormone $(\alpha-G P))$ and a hormone specific $\beta$-subunit. The $\alpha$ - and $\beta$-subunits associate non-covalently and their assembly is obligatory for the biological activity of the hormones (Pierce \& Parson 1981).

Although teleostean LH has been isolated from quite a few species, the identification of FSH in teleosts is a relatively recent advancement and has been isolated from only a few fish species (Itoh et al. 1988, Suzuki et al. 1988, Swanson et al. 1991, Van Der Kraak et al. 1992, Copeland \& Thomas 1993, Koide et al. 1993, Tanaka et al. 1993, Garcia-Hernandez et al. 1997). Unlike LH, teleostean FSH displays high diversity between species and therefore suggests that the use of heterologous FSH for studying its function may not be appropriate (Swanson \& Dittman 1997). Although well studied in mammals, the precise role of each GtH in teleosts is not yet fully clear. As demonstrated with the salmonid model, it is believed that FSH plays a primary role in early stages of gonadal development (Swanson 1991, Campbell et al. 2003), whereas LH is linked to oocyte maturation and ovulation and to spermiation (Swanson et al. 1991, Slater et al. 1994, Kusakabe et al. 2006).

Mammalian recombinant GtHs have been successfully produced and are extensively used for endocrine studies 
(Amano \& Kobata 1993, Szkudlinski et al. 1996, Ben-Menahem et al. 1997) as well as for pharmacological applications (Lathi \& Milki 2001). Although the cDNAs encoding the $\alpha$-GP, $\beta-\mathrm{FSH}$, and $\beta-\mathrm{LH}$ have been isolated from a growing number of teleosts (Schulz et al. 2001), the production of recombinant fish $\mathrm{GtH}$ has been far less successful. There are reports of the production of biologically active recombinant fish GtHs (Kamei et al. 2003, Vischer et al. 2003, Aizen et al. 2007, Cui et al. 2007, Ko et al. 2007); however, an efficient expression technology that addresses all aspects, such as i) biological activity of the resultant recombinant $\mathrm{GtHs}$, ii) productivity in high abundance, and iii) easy protocol of purification, has not been developed for teleosts GtHs.

We have addressed these problems by producing recombinant channel catfish (Ictalurus punctatus; I $p$ ) FSH and LH in a modification of an insect cell (S2) expression system (Drosophila Expression System; Invitrogen). This recombinant protein expression system is based on cells derived from a higher eukaryotic (albeit invertebrate); therefore, they possess the capacity for appropriate post-translational modifications, such as glycosylation.

\section{Materials and Methods}

\section{Construction of expression vectors}

The cDNAs encoding the entire subunits (secretory signal peptide and the mature peptide) of GtHs, $\alpha-\mathrm{GP}, \beta-\mathrm{LH}$, and $\beta$-FSH were amplified by PCR from reverse-transcribed RNA isolated from a channel catfish (I. punctatus) pituitary. $\mathrm{GtH}$-specific primers (based on the sequence published in Liu et al. 1997; GenBank \#AF112191 and AF112192) were designed to eliminate the termination codon and insert AgeI restriction sites. Table 1 provides the sequence of all primers used in this report including the primers for the $\alpha$-GP (primers 1 and 2), $\beta-\mathrm{LH}$ (primers 3 and 4), and $\beta-\mathrm{FSH}$ (primers 5 and 6). PCR amplification was performed using the Advantage 2 PCR kit (BD Biosciences, Palo Alto, CA, USA) under the following conditions: 3-min denaturation at $94{ }^{\circ} \mathrm{C}$ followed by 32 cycles of $94{ }^{\circ} \mathrm{C}$ for $30 \mathrm{~s}, 55^{\circ} \mathrm{C}$ for $30 \mathrm{~s}$, and $72{ }^{\circ} \mathrm{C}$ for $30 \mathrm{~s}$, and 10 -min elongation at $72{ }^{\circ} \mathrm{C}$. Each amplicon was ligated into a pDrive vector (Qiagen), released by EcoRI and AgeI restriction digest, and subcloned into a similarly digested $\mathrm{pMT} / \mathrm{V} 5-\mathrm{His}$ (pMT) expression vector (DES kit, Invitrogen), thereby generating an in-frame hexahistidinyl fusion (His-tag) at the C-terminus (Fig. 1A). These constructs were labeled pMT $\alpha$-His, pMT $\beta$ FSH-His, and $\mathrm{pMT} \beta \mathrm{LH}-\mathrm{His}$. Expression by pMT vectors is driven by the divalent metal inducible metallothionein promoter.

The expression of $\alpha-\mathrm{GP} / \beta-\mathrm{FSH}$ and $\alpha-\mathrm{GP} / \beta-\mathrm{LH}$ heterodimeric hormones was encoded by a modified pMT/V5-His vector engineered to contain two inducible promoters for the simultaneous expression of the two subunits (pMT $\alpha / \beta F S H$ and $\mathrm{pMT} \alpha / \beta \mathrm{LH})$. In order to avoid potential steric hindrance by the His-tag, the $\alpha$-GP amplicon (using primers 1 and 7; Table 1) for these constructs was generated with its native stop codon intact thus lacking the His-tag fusion. This $\alpha-G P$ amplicon was inserted, as described above, into a pMT vector in order to generate the $\mathrm{pMT} \alpha$ construct. In another PCR amplification using primers 8 and 9 (Table 1), a high-fidelity DNA polymerase (Herculase, Stratagene, La Jolla, CA, USA) and pMT $\beta F S H-H i s$ or pMT $\beta \mathrm{LH}-\mathrm{His}$ as template, an amplicon was generated containing the sequence for the metallothionein promoter, the $\beta$-subunit, the His-tag, and the termination signal. After digestion with Nar I and Aat II, these amplicons were ligated separately into a similarly digested pMT $\alpha$ vector constructs (Fig. 1B).

\section{Production and purification of recombinant proteins}

Transfection, selection, maintenance, and induction of expression of the Schneider's S2 cell line were performed according to the manufacturer's protocol (Drosophila Expression System, DES, Invitrogen). Described in brief, each of the GtH constructs were co-transfected with the pCoBlast selection vector (included in the kit) into S2 cells using Effectene transfection reagent (Qiagen). Transfected cells were selected for a period of 2 weeks in a 'complete medium' composed of Schneider Insect Medium (Sigma Chemicals) supplemented with Yeastolate 10000 molecular weight cut-off (MWCO) Ultrafiltrate, chemically defined

Table 1 Oligonucleotide primers used for PCR amplification of the three Ip gonadotropin subunits and for real-time quantitative RT-PCR assays. Introduced restriction sites are underlined. F, sense primer; R, antisense primer

\section{Name and direction}

$\begin{array}{ll}\text { Primer no. } & \\ 1 & \text { Ip- } \alpha-F \\ 2 & \text { Ip- } \alpha-R \\ 3 & \text { Ip-LH-F } \\ 4 & \text { Ip-LH-R } \\ 5 & \text { IP-FSH-F } \\ 6 & \text { IP-FSH-R } \\ 7 & \text { Ip- } \alpha \text { Stop-R } \\ 8 & \text { pMT-F } \\ 9 & \text { pMT-R }\end{array}$

Sequence

5' GAGGAAGAAGAGAAGACTGTCT 3'

5' GAACCGGTAAATTTATGATAGTAACAAGTGCTGCAAT 3'

5' CA AAATCTCTAAAGATGTCAGTGCC $3^{\prime}$

$5^{\prime}$ GAACCGGTGTAATCCAGGATGTACTCTTTCTG $3^{\prime}$

5' GAATTCGGCACGAGGGTGAT 3'

5' CTTACCGGTGTAGTAGGCGTGTGTGTGG3'

5' GAACCGGTCAAAATTTATGATAGTAACAAGTGC 3'

5' GAGGCGCCGTTGCAGGACAGGATGT 3'

5' CTGACGTCTTGTTGTTGTTAACTTGTT 3' 


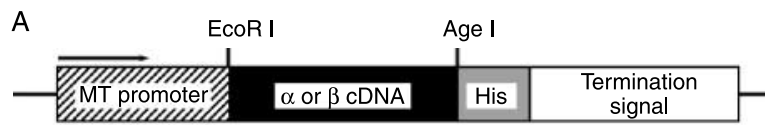

B

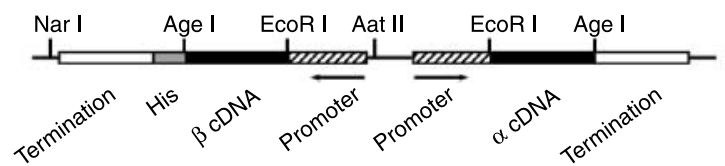

Figure 1 Schematic representation of a portion of the expression vector constructs. (A) Expression elements of the pMT $\alpha$-His, pMT $\beta F \mathrm{SH}-\mathrm{His}$, and pMT $\beta \mathrm{LH}-\mathrm{His}$ vectors. (B) Expression elements of the dual promoter $\mathrm{pMT} \alpha / \beta \mathrm{FSH}$ and $\mathrm{pMT} \alpha / \beta \mathrm{LH}$ transfer vectors. Hatched box, metalothionein promoter; solid box, gonadotropin subunit cDNA; gray box, His-tag fusion; and open box, termination signal.

Lipid Concentrate (both from Life Technologies, Gaithersburg, MD, USA), blasticidin S ( $25 \mu \mathrm{g} / \mathrm{ml}$; Invitrogen), and $10 \%$ heat-inactivated fetal calf serum (FCS). After selection and expansion, the cells were transferred to a baffled shake flask in complete medium containing a reduced concentration of blasticidin $(10 \mu \mathrm{g} / \mathrm{ml})$ and grown to a density of 20 $30 \times 10^{6} \mathrm{cells} / \mathrm{ml}$ in a volume of $500 \mathrm{ml}$. At this point, the complete medium was replaced with 11 serum-free, antibiotic-free medium (complete medium lacking the FCS and Blasticidin). After an adaptation period of 3 days (cell density of $15 \times 10^{6}$ cells $/ \mathrm{ml}$ ), protein expression was induced by the addition of $\mathrm{CuSO}_{4}(500 \mu \mathrm{M})$. After 4 days, the medium was harvested, clarified by centrifugation, sequentially filtered through $100000 \mathrm{MWCO}$ and $10000 \mathrm{MWCO}$ ultrafiltration membranes (Millipore Corporation, Bedford, MA, USA). The retentates from both ultrafiltration steps were passed through an immobilized metal affinity chromatography (IMAC) column (Talon metal affinity; Clontech, Palo Alto, CA, USA) according to the manufacturer's protocol. In order to produce highly purified I $p$ LH and FSH, IMAC-purified rec-GtHs were further subjected either to size-exclusion HPLC using Superdex 75 column equilibrated with $250 \mathrm{mM}$ Tris-HCl, pH 7-2 (AKTA 10S, Amersham) or were subjected to ethanol precipitation for preparation of the glycoprotein fraction as described by Mananos et al. (1997).

\section{Gel electrophoresis and western blot analysis}

PAGE was performed using 4-20\% gradient denaturing gels or $12 \%$ non-denaturing gels (Bio-Rad). Tris/glycine/SDS running buffer (Bio-Rad) was used for denaturing electrophoresis, and the same buffer lacking the SDS was used for non-denaturing electrophoresis. Abundant proteins were visualized with gelCode Blue stain (Pierce, Rockford, IL, USA).

Proteins in non-stained gels were electrophoretically transferred onto Nytran membrane (Schleicher \& Schuell, Keene, NH, USA) in preparation for immunoblotting. The membranes were incubated with either rabbit anti-African catfish $\alpha$-GP (1:10 000) or with rabbit anti-striped bass $\beta$-LH in TBS-T buffer containing 5\% skimmed milk powder, washed, and incubated with 1:5000 goat anti-rabbit IgG-HRP conjugate (Bio-Rad). The rec-GtHs were also analyzed by western blot using His-tag-specific INDIAHisProbe-HRP (Pierce) following the manufacturer's instruction. The luminescent signal emitted by the Super Signal West Pico substrate (Pierce) was detected with X-ray film.

In order to estimate the purity of IMAC-purified rec-FSH or rec-LH, the proteins were resolved on a non-denaturing PAGE (see Fig. $3 \mathrm{Ba}$ ), stained, and scanned using an Epson perfection 3200 scanner (Epson, Long Beach, CA, USA). The bands were quantified densitometrically using a PC-based image analysis system and a program developed in the KS400 version 3.0 software package (Carl Zeiss Vision, Göttingen, Germany). The bands were delimited using a threshold-dependent gray level of the local neighborhood area, before the integrated optical density of each band of interest was determined separately, and then expressed as percentage of the total optical density of the respective lane.

\section{Receptor binding and activation}

Recombinant Ip FSH receptor (rec-FSH-R) and LH receptor (rec-LH-R) transiently expressed in COS cells were previously demonstrated to respond to heterologous $\mathrm{FSH}$ and $\mathrm{LH}$ (Kumar et al. 2001a,b). Using this system, COS cells, expressing rec-FSH-R and rec-LH-R along with a cAMPresponsive luciferase reporter system, were incubated for $6 \mathrm{~h}$ with IMAC-purified Iprec-LH and rec-FSH $(0-200 \mathrm{ng} / \mathrm{ml})$ in order to determine their ability to bind and activate the receptors. Activation of the receptors was indirectly quantified by luciferase activity (Luciferase Assay kit; Promega Corporation) using a MicroLumat LB96P luminometer (EG\&G Berthold, Stammwerk Wilbad, Germany).

In vitro hormonal treatment of channel catfish ovarian follicles with rec-GtH

The biological activity of the rec-LH and rec-FSH was further tested for their ability to induce $\mathrm{E}_{2}$ secretion from $I p$ ovarian follicles in vitro. Ovarian follicles $(100 \mathrm{mg})$ from a catfish ovary with a GSI of 8 (i.e. in late or post-vitellogenic growth phase) were incubated in $1 \mathrm{ml}$ of $75 \% \mathrm{~L}-15$ medium supplemented with HEPES (15 mM; pH 7•4) and various concentrations of IMAC-purified rec-LH and rec-FSH $(0 \cdot 2-150 \mathrm{ng} / \mathrm{ml})$ in triplicates. After $15 \mathrm{~h}$ of incubation, the $\mathrm{E}_{2}$ concentration in the medium was determined by specific RIA (DPC, Los-Angeles, CA, USA) and the abundance of the ovarian aromatase (CYP19, P450arom) transcript in the tissues was also determined by real-time quantitative RT-PCR (rtqRT-PCR: Kumar et al. 2000). In order to further clarify the bioactivity of I $p$ rec-GtHs and to compare the activity with that of hCG that has often been used to investigate the action of $\mathrm{GtH}$ in fish, ovarian follicles at the post-vitellogenic stage 
$(\mathrm{GSI}=12)$ were incubated with either Ip rec-GtHs $(100 \mathrm{ng} / \mathrm{ml})$ or human chorionic gonadotropin (hCG; $30 \mathrm{IU} / \mathrm{ml})$. Changes in the expression of genes associated with reproduction, i.e., four steroidogenic enzymes (P450scc, P450c17, P450arom, and 3ß-HSD; Kumar et al. 2000) and two GtH receptors (FSH-R and LH-R; Kumar et al. 2001a,b) were determined by rtqRT-PCR. Ovarian tissues were flash frozen and stored at $-80{ }^{\circ} \mathrm{C}$ until analyses. The procedures for the care and use of the catfish were approved by the Center's and University's IACUC.

\section{In vitro hormonal treatment of African catfish testis with Ip} rec-GtH

Using the established method in African catfish (Vischer et al. 2003), the bioactivity of $\mathrm{GtH}$ in testicular steroidogenesis was examined. In brief, for each experiment testis, tissue was collected from three fully mature males of 12-14 months of age. The tissue was pooled in a Petri dish containing Dulbecco's Modified Eagle's medium (DMEM)-HEPES (Sigma) supplemented with L-glutamine $(8 \mathrm{mM})$, and penicillin $\mathrm{G}$ and streptomycin $(100 \mathrm{U} / \mathrm{ml}$ each; all from Invitrogen). While submerged in medium, the tissue was minced into fragments of 2-3 $\mathrm{mm}^{3}$. The fragments were filtered over two layers of cheesecloth, pre-incubated in fresh medium in a shaking incubator at $25^{\circ} \mathrm{C}$ for $30 \mathrm{~min}$, and filtered again over two layers of cheesecloth, to remove suspended sperm and tissue debris. Four or five randomly selected fragments (total wet weight 20$30 \mathrm{mg}$ ) were placed per well of a 24-well culture plate containing $0.2 \mathrm{ml}$ medium. Six replicates per ligand concentration were tested in dose-response experiments. The tissue fragments were incubated at $25^{\circ} \mathrm{C}$ for $18 \mathrm{~h}$ in the presence of varying concentrations of IMAC-purified recombinant hormones as indicated. The incubation medium was then collected, heated at $80^{\circ} \mathrm{C}$ for $1 \mathrm{~h}$, and centrifuged at $16000 \mathrm{~g}$ at room temperature for $30 \mathrm{~min}$. The supernatants were stored at $20^{\circ} \mathrm{C}$ until the secreted androgen (4-androsten-11ß-ol-3, 17-dione; OHA) levels were determined by RIA as described previously (Schulz et al. 1996). OHA is the quantitatively dominating androgen secreted by African catfish testis (Vermeulen et al. 1993). The results are expressed as nanograms of OHA secreted per milligram of testis tissue incubated.

\section{Measurement of transcript abundance of genes in i.p. ovarian follicles}

One microgram of total RNA was extracted from ovarian samples using Trizol Reagent (Life Technologies) and reverse transcribed using random hexamer primers. Analyses by rtqRTPCR assays (Kumar et al. 2000, 2001a,b) were performed in duplicate $20 \mu \mathrm{l}$ PCRs using SYBR Green Core Reagents (PE Applied Biosystems, Foster city, CA, USA) and an ABI Sequence Detector 7700 to determine the transcript abundance of target genes, specifically, four steroidogenic enzymes and the two GtH receptors. Abundance of the gene transcript was normalized to that of $\beta$-actin (Kumar \& Trant 2004) and reported as a fold change in abundance relative to the sample with the lowest level of expression.

\section{Statistical analysis}

All numerical data are presented as means \pm s.E.M. Statistical differences to control were determined by one-way ANOVA followed by Fisher's PLSD post hoc test.

\section{Results}

The following results clearly show that biologically active recombinant catfish $\mathrm{FSH}$ and $\mathrm{LH}$ can be produced in abundance using a modification of a commercially available Drosophila cell expression system. The resultant recombinant proteins were significantly purified by IMAC and sizeexclusion chromatography, and biological activity of IMACpurified Ip rec-GtHs suggests important endocrine differences in their mode of action and physiological roles.

\section{Production of Ip $\alpha-G t H, \beta-L H, \beta-F S H$ subunits}

The cDNAs encoding the three different GtH subunits were initially introduced individually into the pMT/V5-His vector and expressed in S2 cells. During the selection period, cells seemed to grow normally and were capable of expressing the appropriate subunits as determined by western blot analysis using a specific anti-His probe and/or specific antibodies to

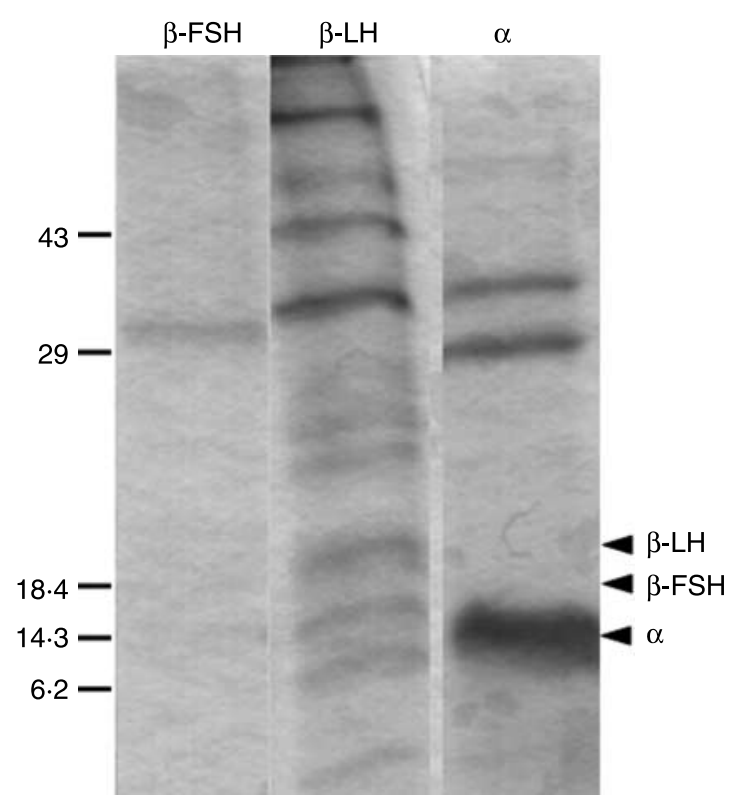

Figure $24-20 \%$ SDS-PAGE analysis of IMAC purified Ip GtH subunits ( $\beta-\mathrm{FSH}, \beta-\mathrm{LH}, \alpha-\mathrm{GP}$ ) isolated from conditioned medium of $\mathrm{S} 2$ cells transfected with vectors encoding individual subunits. Molecular weight markers $(\mathrm{kDa})$ and the expected location of each subunit (arrows) are indicated. 
subunit proteins, i.e. anti-African catfish $\boldsymbol{\alpha}$-GP $(1: 10000)$ and anti-striped bass $\beta-\mathrm{LH}$ (data not shown). However, upon continued culture of the recombinant cells expressing the $\beta-\mathrm{LH}$ and $\beta$-FSH subunits alone, significant cell death resulted and marginal amounts of recombinant protein were detected. SDS-PAGE analysis of the IMAC-purified proteins revealed that $\alpha$-GP, at the expected size of $\sim 15 \mathrm{kDa}$, abundantly accumulated in the medium, while the $\beta-\mathrm{LH}$ and $\beta-\mathrm{FSH}$ subunits, at the size of 21 and $20 \mathrm{kDa}$ respectively, were poorly produced (Fig. 2). The $\beta$-subunits were undetectable in cell extracts (data not shown), suggesting that the $\beta$-subunits were either intrinsically poorly expressed, the $\beta$-monomers were unstable, or the $\beta$-peptides were toxic to the cell.

The strategy of producing both $\alpha$ - and $\beta$-subunits simultaneously in the same cell as mediated by the dual promoter vectors, i.e. $\mathrm{pMT} \alpha / \beta \mathrm{FSH}$ and $\mathrm{pMT} \alpha / \beta \mathrm{LH}$, significantly improved yields. Two major bands matching the expected sizes of $\alpha$-GP and $\beta$-FSH or $\beta$-LH were visualized by protein stain after SDS-PAGE of IMAC-purified GtHs (Fig. 3Aa). It has been confirmed that these bands were not observed in the IMAC-purified protein from culture media of S2 cells transfected with the empty vector (data not shown). Western blot analysis of the proteins using antiserum raised against the $\alpha$-GP of the African catfish confirmed the identity of the abundant $15 \mathrm{kDa}$ protein as recombinant $\alpha$-GP subunit (Fig. 3Ab). The identity of the 20 and $21 \mathrm{kDa}$ protein signals were confirmed for $\mathrm{FSH}$ and $\mathrm{LH}$ respectively by western blot for detection of His-tagged protein (Fig. 3Ac). Furthermore, an antiserum against the $\beta-\mathrm{LH}$ of the striped bass also clearly recognized the $21 \mathrm{kDa}$ protein (data not shown), while, due to the lack of antiserum cross-reacting with catfish $\beta$-FSH, the immunochemical identification of the $20 \mathrm{kDa}$ protein was not confirmed as $\beta-\mathrm{FSH}$.
Non-denaturing acrylamide gel electrophoresis was used to evaluate the association of the native recombinant proteins. The most abundant stained protein was the larger of the two and one major bands in the rec-FSH and rec-LH sample respectively (Fig. 3Ba). Western blot analysis revealed that the anti- $\alpha-G P$ recognizes the largest major band of rec-FSH and LH preparations (Fig. 3Bb). Furthermore, the identical larger protein of the rec-LH was labeled with the anti- $\beta-\mathrm{LH}$, indicating that the protein is a heterodimer consisting of both $\alpha-\mathrm{GP}$ and $\beta-\mathrm{LH}$ subunits (Fig. $3 \mathrm{Bc}$ ). The smaller protein may be free $\beta-\mathrm{LH}$ (Fig. $3 \mathrm{Bc}$ ). It should be noted that the anti-striped bass $L H \beta$ reacted with a protein pituitary extract of catfish in a native PAGE, at a position similar to that of the higher molecular weight band of Ip rec-LH, the putative heterodimeric LH (supplementary data; see supplementary figure in the online version of the Journal of Endocrinology at http://joe.endocrinology-journals.org/content/vol194/ issue2). There was no evidence of free $\alpha-G P$ in either the rec$\mathrm{LH}$ or the rec-FSH preparations (Fig. 3Bb). Western blot analysis using His-probing was also carried out for the recGtHs under native conditions; however, specific signals could not be visualized (data not shown).

The purity of the IMAC prepared rec-FSH and rec-LH was densitometrically determined to be 15 and $16 \%$ respectively (native PAGE analysis). In combination with a total protein Lowery assay, the yield of IMAC-purified, heterodimeric hormone from each of two production trials was estimated to be 6 and $7 \mathrm{mg} / \mathrm{l}$ of culture medium for rec-FSH and 4 and $3 \mathrm{mg} / 1$ for rec-LH. Additionally, a small portion of the IMAC-purified hormone preparations was further purified by size-exclusion chromatography with Superdex 75 or ethanol precipitation of the glycoprotein fraction. SDS-PAGE followed by gelCode blue stain of the resultant rec-GtHs visualized only two protein bands corresponding to
A: SDS-page

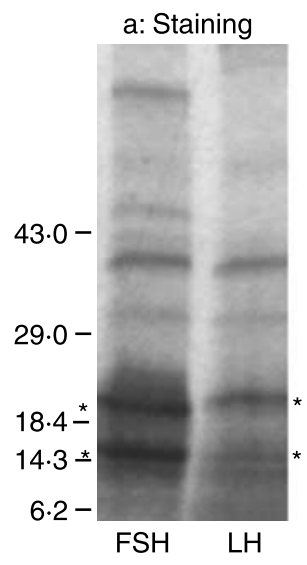

b: Anti- $\alpha-G P \quad$ c: His-probe

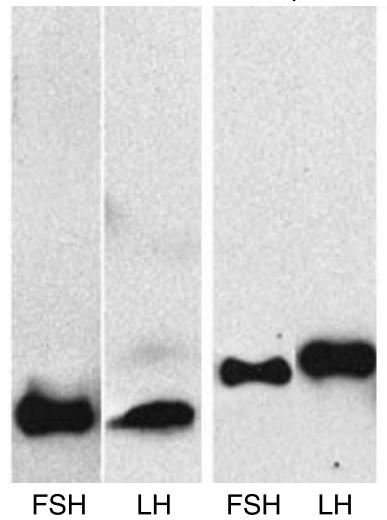

B: Native page

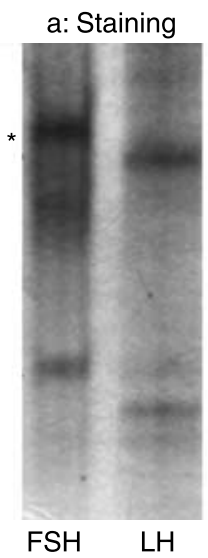

d: Anti-LH $\beta$

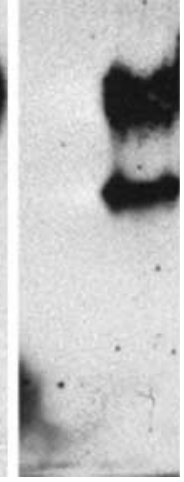

Figure 3 PAGE and immunoblot analyses of the IMAC-purified rec-FSH and rec-LH isolated from conditioned medium of S2 cells transfected with the dual promoter vectors encoding both the $\alpha$ - and the respective $\beta$-subunit. (A) Denaturing SDS-PAGE; (B) native PAGE. a: Total proteins (protein stain); b: immunoblot with antiAfrican catfish $\alpha$-GP; c: western blot with His-probe; d: immunoblot with anti-striped bass $\beta$-LH. Asterisks point to the putative subunits (A) or the heterodimers (B) of rec-GtHs. 
$\alpha$ - and $\beta$-subunits (data not shown). The resultant yield of the highly purified rec-GtHs was below the detection limit of the protein assay; therefore, the readily quantifiable IMACpurified preparations were used to demonstrate bioactivity of these preparations (see below).

\section{Receptor binding and activation of $C A M P$ production in vitro}

An efficient functional expression system in COS cells for channel catfish rec-FSH receptor (FSH-R) and rec-LH-R was previously developed (Kumar et al. 2001a, b). In these earlier studies, it was shown that heterologous FSH and LH activated the respective catfish $\mathrm{GtH}$ receptors when produced in COS cells. We used this system to verify the biological activity of Ip rec-FSH and rec-LH preparations. As seen in Fig. 4A, rec-FSH efficiently activated FSH-R in a dose-dependent manner. A concentration of $50 \mathrm{ng} / \mathrm{ml}$ total protein of the IMACpurified preparation (an estimated $7.5 \mathrm{ng} / \mathrm{ml} \mathrm{rec-FSH}$ ) was sufficient to induce cAMP-dependent luciferase expression by sixfolds and $100 \mathrm{ng} / \mathrm{ml}$ total protein (estimated $15 \mathrm{ng} / \mathrm{ml}$ rec-FSH) resulted in a maximal induction of $7 \cdot 6$-fold above control. As found by us before, rec-LH also activated

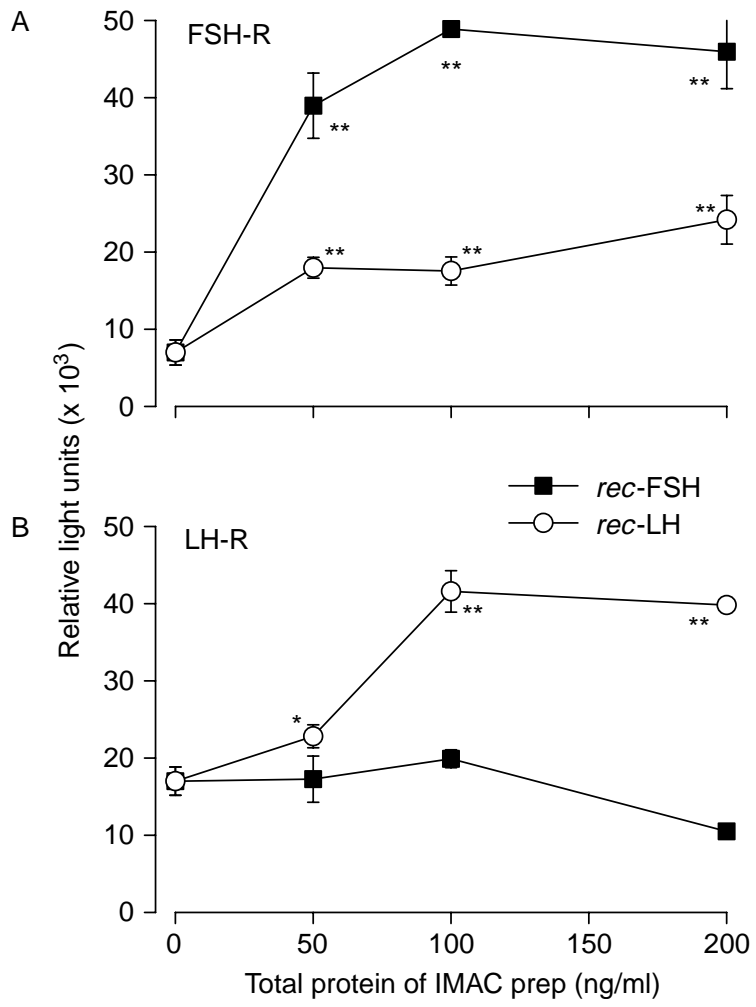

Figure 4 Activation of Ip FSH-R (A) and LH-R (B) expressed in COS cells by the rec-GtHs. An increase in the relative light units (means \pm s.E.M.) produced by the cells that were transiently co-transfected with a cAMP responsive reporter gene (luciferase) and Ip FSH-R or Ip LH-R constructs is due to a GtH-mediated increase of cAMP. Statistical analysis: one-way ANOVA followed by Fisher's PLSD post hoc test. ${ }^{*} P<0 \cdot 05,{ }^{* *} P<0 \cdot 01$. the FSH-R; however, it was $1 \cdot 8$ - to $2 \cdot 8$-fold less potent than rec-FSH at all concentrations tested (Fig. 4A). Again, as found by us before, rec-LH, but not rec-FSH, activated the LH-R. A concentration of $50 \mathrm{ng} / \mathrm{ml}$ total protein of the IMAC preparation (estimated $7.5 \mathrm{ng} / \mathrm{ml}$ rec-LH) induced a $1 \cdot 3$-fold increase in the activity of the reporter gene and $100 \mathrm{ng} / \mathrm{ml}$ total protein $(15 \mathrm{ng} / \mathrm{ml} \mathrm{rec}-\mathrm{LH})$ resulted in a maximal stimulation of $2 \cdot 5$-fold (Fig. 4B).

\section{Bioactivity of rec-LH and rec-FSH in catfish gonads}

In order to determine whether rec-GtH preparations were also active when incubated with their homologous target tissue and to verify possible differential bioactivity of FSH and $\mathrm{LH}$, we tested their ability to induce steroidogenesis in Ip ovarian follicles and African catfish testis. The dose-dependent effect of the rec-FSH and rec-LH preparations on steroidogenesis in vitellogenic $I p$ follicles was determined by the changes in $\mathrm{E}_{2}$ secretion and P450arom gene regulation (transcript abundance). As seen in Fig. 5A, both $\mathrm{LH}$ and FSH induced $\mathrm{E}_{2}$ secretion in a dose-dependent manner. In follicles of this
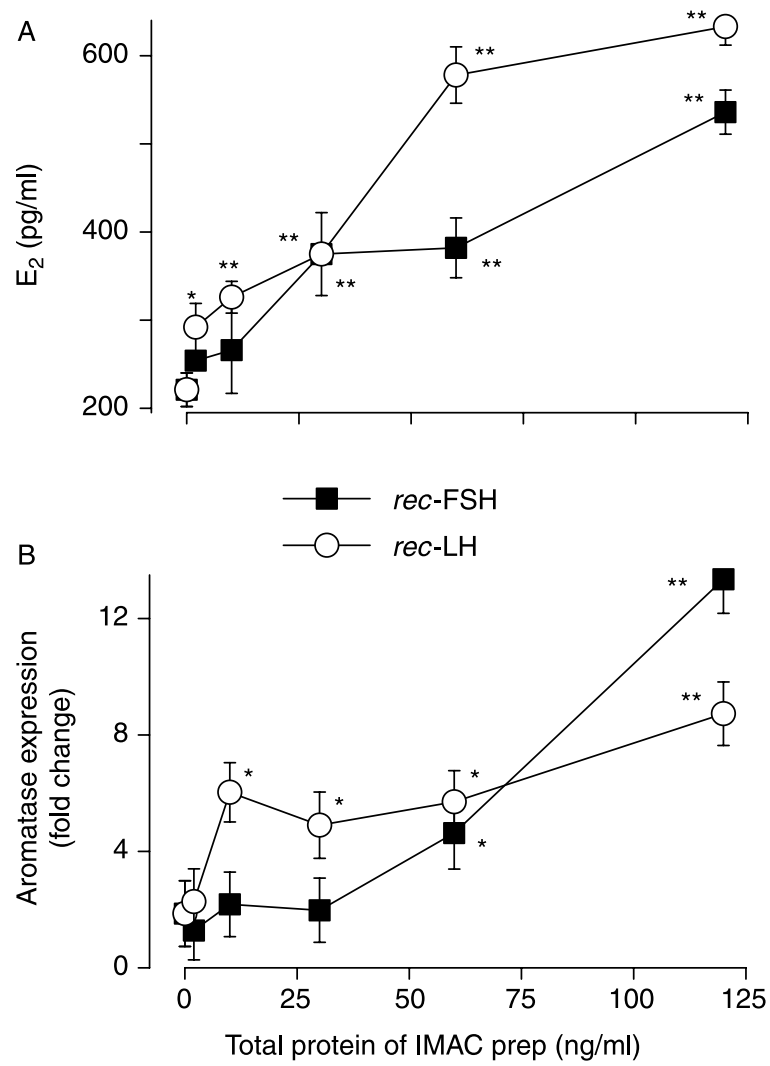

Figure 5 Concentration response of $I p$ oocytes in the midvitellogenic growth phase to Ip rec-FSH and Ip rec-LH. Changes in estradiol $\left(\mathrm{E}_{2}\right)$ concentration $(\mathrm{A})$ and aromatase gene expression (B); transcript abundance) are presented as mean \pm s.E.M. of triplicate observations. Statistical analysis: one-way ANOVA followed by Fisher's PLSD post hoc test. ${ }^{*} P<0 \cdot 05,{ }^{* *} P<0 \cdot 01$. 
reproductive stage, rec-LH was more potent than rec-FSH. A dose of $10 \mathrm{ng} / \mathrm{ml}$ total protein $(1.5 \mathrm{ng} / \mathrm{ml}$ rec $-\mathrm{LH})$ significantly increased $\mathrm{E}_{2}$ secretion by $150 \%$ and a maximal increase of $280 \%$ was obtained with $120 \mathrm{ng} / \mathrm{ml}$ total protein $(18 \mathrm{ng} / \mathrm{ml}$ rec-LH; Fig. 5A). The rec-FSH significantly induced $\mathrm{E}_{2}$ secretion by $240 \%$ at a relatively high dose of $120 \mathrm{ng} / \mathrm{ml}$ total protein $(18 \mathrm{ng} / \mathrm{ml} \mathrm{rec-FSH}$; Fig. 5A). P450arom expression in the vitellogenic ovarian tissues was readily up-regulated threefold at a dose of $10 \mathrm{ng} / \mathrm{ml}$ total protein $(1.5 \mathrm{ng} / \mathrm{ml} \mathrm{rec-LH})$; however, only moderate increases in the transcription was evident with further increases of rec-LH concentration (Fig. 5B). P450arom was significantly up-regulated with a minimum concentration of $60 \mathrm{ng} / \mathrm{ml}$ IMAC preparation ( $9 \mathrm{ng} / \mathrm{ml} \mathrm{rec} \mathrm{FSH})$ and could be maximally induced to $720 \%$ above control (Fig. 5B).

Both IMAC-purified rec-GtHs induced the release of OHA (the primary testicular androgen) from African catfish
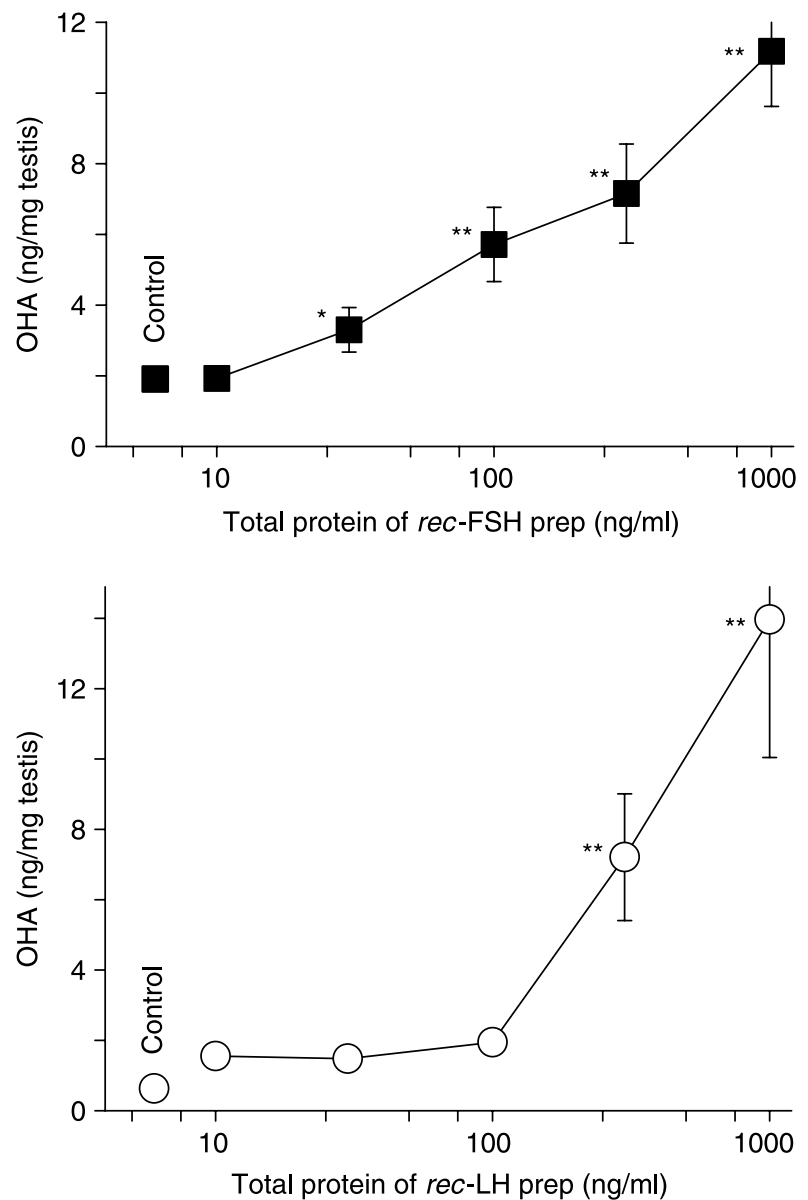

Figure 6 Concentration response of African catfish testis to Ip rec-FSH and Ip rec-LH. Changes in $\mathrm{OHA}$ concentration in the media are presented as mean \pm S.E.M. of triplicateobservations. Note the log scale of the axis for GtH concentration. Statistical analysis: one-way ANOVA followed by Fisher's PLSD post hoc test. $* P<0 \cdot 05, * * P<0 \cdot 01$. testis in a dose-dependent manner (Fig. 6). At concentrations lower than $15 \mathrm{ng} \mathrm{GtH} / \mathrm{ml}$ (100 $\mathrm{ng} / \mathrm{ml}$ IMAC protein), the steroidogenic activity of rec-FSH seems to be higher than that of rec- $\mathrm{LH}$; however, these rec-GtHs behaved similarly at the higher doses (>45 ng GtH/ml; $300 \mathrm{ng} / \mathrm{ml}$ IMAC protein).

For further assurance of the bioactivity of the rec-GtHs, the regulation of the genes associated with ovarian reproductive physiology, i.e. four key steroidogenic enzymes and the two $\mathrm{GtH}$ receptors, were examined in ovarian follicles at or near the post-vitellogenic stage of gametogenesis (Fig. 7). Treatment with rec-LH up-regulated the expression of all genes except FSH-R, whereas hCG induced only P450scc, P450arom, and 3 $\beta-\mathrm{HSD}$ (Fig. 7). In contrast, rec-FSH treatment enhanced transcriptional activity for $3 \beta-\mathrm{HSD}$ gene only, although the transcript abundance of P450scc and P450arom tended to be higher than that of the control group. It also should be noted that the average Ct values (number of PCR cycles required for the signal to surpass a set threshold) for actin transcript abundance were not
P450scc

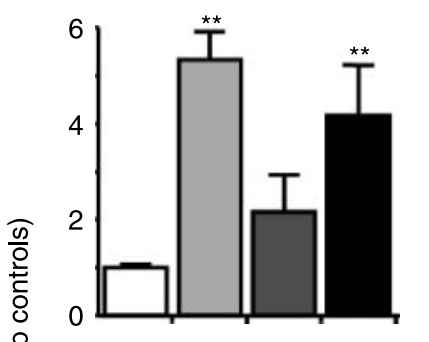

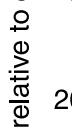

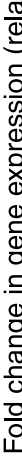

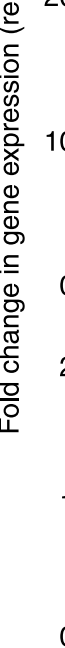

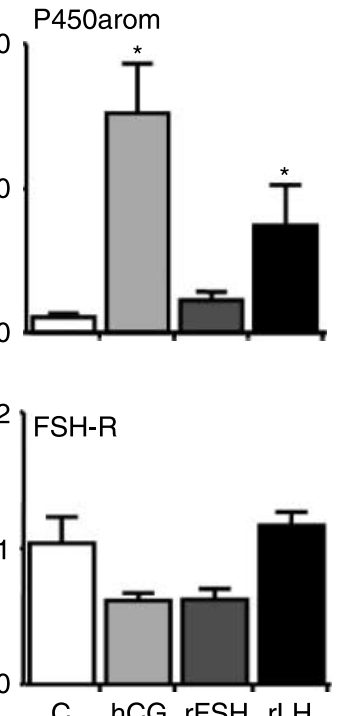

$P 450 c 17$
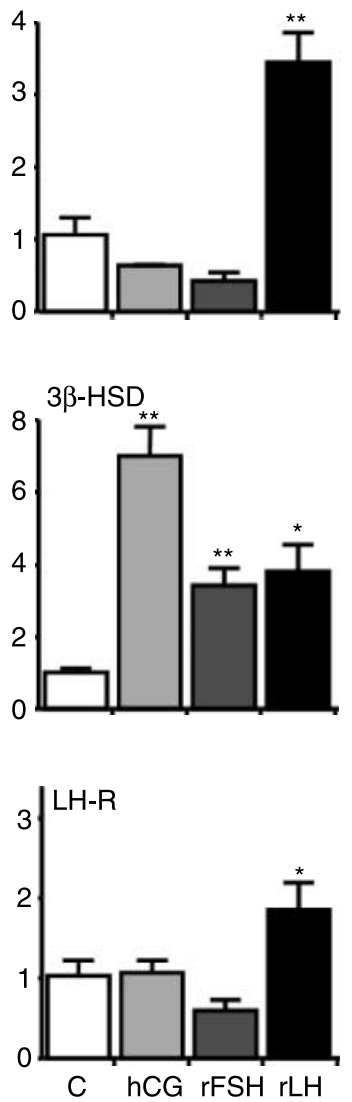

Figure 7 Hormonal regulation of gene expression of four steroidogenic enzymes and the two GtH-Rs by Ip rec-GtHs and hCG. Changes in transcript abundances of the genes are presented as mean \pm S.E.M. of triplicate observations. Statistical analysis: one-way ANOVA followed by Fisher's PLSD post hoc test. ${ }^{*} P<0 \cdot 05,{ }^{* *} P<0 \cdot 01$. 
statistically different between the experimental groups compared here.

\section{Discussion}

In this study, an efficient protocol for the abundant production of biologically active recombinant channel catfish gonadotropins was developed utilizing a modification of a commercially available eukaryotic expression cell system. The recombinant Drosophila S2 cells were grown to high density in a suspension culture of a relatively inexpensive, supplemented Schneider's Medium. Expression was induced in a similarly formulated serum-free medium. Fortunately, fusion of the His-tag onto the $\beta$-subunits (but not the $\alpha$-subunit) did not sterically hinder dimerization or receptor binding yet it remained available for IMAC purification. The insect cells presumably recognized the teleostean secretory signal of the $\mathrm{GtH}$ subunits since the GtHs were found exclusively in the medium. Although we have no data demonstrating the type or degree of glycosylation of $\mathrm{rec}-\mathrm{GtHs}$, the structural features of recombinant proteins were compatible with heterodimerization of the $\alpha$-and $\beta$-subunits in a manner that allowed the formation of proteins recognized by and able to activate their cognate receptors. Although both recombinant GtHs stimulated ovarian steroidogenesis, there appear to be important differences in the intrinsic response elicited by both hormones. Due to the lack of contamination of a recombinant $\mathrm{GtH}$ with the reciprocal $\mathrm{GtH}$ or TSH, which is problematic with purified preparations of native $\mathrm{GtH}$ derived from pituitaries (Pierce \& Parsons 1981), these GtHs and this methodology will provide the required reagents to address questions about hormone-specific actions throughout a reproductive cycle in specific target tissues.

Of the three subunits expressed independently, only the $\alpha-G P$ subunit was successfully produced in abundance as a single subunit (Fig.2). However, co-expression of the $\alpha$-GP subunit with a significant $\beta-\mathrm{FSH}$ or $\beta$-LH subunit resulted in the significantly greater yield. Similarly, it has been demonstrated that transfected $\mathrm{CHO}$ cells readily secreted ovine $\alpha$-GP but not the $\beta$-FSH subunit and co-expression of both subunits led to heterodimer assembly and efficient secretion (Mountford et al. 1994).

Densitometric analysis showed that hormone contents in the IMAC-purified rec-GtHswere $\sim 15 \%$, resulting in a recovery of $7 \mathrm{mg}$ rec-FSH and $4 \mathrm{mg}$ rec-LH per liter of medium by a simple three-step purification system (i.e. two ultrafiltration steps for buffer exchange followed by passage through a single IMAC column). These results are significantly greater than the yield from other heterologous expression systems such as the soil amoeba $(<80 \mathrm{ng} / \mathrm{ml}$; Vischer et al. 2003) for GtH production of another catfish species, African catfish. The only expression system of fish $\mathrm{GtH}$ with comparable yield and purity to S2 cell system seems to be silkworm larvae (60-180 $\mu \mathrm{g}$ /larvae; Ko et al. 2007). Further optimization of purification protocol will certainly lead to enhance hormone recovery and purity. Although $\mathrm{CHO}$ cells were reported to be relatively efficient when expressing rat FSH $(2 \mu \mathrm{g} / \mathrm{ml}$; Hakola et al. 1996) and $\mathrm{LH}$ $(1 \mu \mathrm{g} / \mathrm{ml}$; Hakola et al. 1997), this expression system has proven to be much less efficient with regards to the production of fish GtHs (Kumar \& Trant, unpublished data).

Immunoblots of electrophoresed proteins clearly showed that both $\alpha$ - and $\beta$-subunits were simultaneously produced by the S2 cells transfected with the dual promoter vectors (Fig. 3). In addition, the formation of $\mathrm{LH}$ heterodimer was demonstrated by the recognition of the same proteins by both anti- $\alpha-$ GP and anti- $\beta-\mathrm{LH}$ antibodies in blots of the native PAGE gels. Even without an antibody against the $\beta-\mathrm{FSH}$ subunit, indirect proof for the heterodimerization of FSH is provided by the immunovisualization of the proteins (the one upper band in Fig. 3Ba) in the IMAC-purified rec-FSH preparation by the anti- $\alpha-G P$ antibody. Since the rec- $\alpha-G P$ encoded by this set of dual-promotor vectors does not contain a His-tag (and therefore is unlikely to bind to the IMAC matrix), the retention of the visualized $\alpha$-GP protein is likely due to its association with the His-tagged $\beta$-FSH subunit.

In the established reporter assay using recombinant catfish FSH-R and LH-R, both rec-GtHs were shown to activate their corresponding receptor. In addition, it should be noted that the FSH-R was activated by both rec-FSH and rec-LH (Fig. 4) as previously reported using mammalian GtHs (Kumar et al. 2001a,b). The possibility that His-tagging with the $\beta$-subunit interfered with the recombinant GtH's receptor specificity and/or affinity could not be ruled out. However, LH-mediated activation of the FSH-R by the recombinant protein without His-tag or by native pituitary $\mathrm{LH}$ has been reported in several fish species including the zebrafish (So et al. 2005), African catfish (Vischer et al. 2003), and salmon (Swanson \& Dittman 1997). We have also confirmed that the IMAC-purified protein from culture media of control cells (S2 cells stably transfected with the empty pMT) is incapable of activating either FSH-R or LH-R (Japanese eel receptors; data not shown).

To verify the biological activity of rec-GtHs in their natural target tissue, their ability to induce $E_{2}$ secretion and gene expression of P450arom was examined using the ovarian follicles in mid-vitellogenic growth. Both parameters were significantly induced essentially in a dose-dependent manner. These data suggest that enhanced steroid production is due to the up-regulation of P450arom gene and possibly other steroidogenic enzymes. However, the dose-response curves, the potency, and the maximal induction with rec-FSH and rec-LH varied, thereby suggesting a differential action of FSH and LH on steroidogenesis in catfish ovary at least in the vitellogenic stage of development. Interestingly, stimulation of androgen release by the African catfish testis also showed differential effects, particularly in the lower doses range where rec-FSH was more potent than rec-LH. Although no information is available yet on the molecular and cell biological basis for this strong steroidogenic activity of FSH, this aspect of piscine FSH bioactivity has been described 
previously in other teleost species (e.g. Planas \& Swanson 1995). As a further support, FSH was shown to have a role in moderating basal and LH-stimulated androgen production, where circulating androgen levels and the responsiveness to exogenous LH were reduced due to a loss of FSH receptor function in mice (Krishnamurthy et al. 2001). Furthermore, it has also been confirmed that the concentration of eel FSH to activate the FSH receptor is much lower than that of eel $\mathrm{LH}$ to activate the $\mathrm{LH}$ receptor using homologous recombinant GtHs produced by S2 cells (data not shown), which reinforces the hypothesis of differential actions of FSH and $\mathrm{LH}$ on the gonadal steroidogenesis in fish.

Further examination of the hormonal regulation of the genes encoding the steroidogenic enzymes and the GtH receptors in ovarian follicles in the post-vitellogenic stage of development using the rec-GtHs and a heterologous GtH, hCG, revealed differential actions of these gonadotropic reagents on the ovary. The effects of rec-LH and hCG were similar but with important differences, such as P450c17 and LH-R genes were up-regulated by the rec-LH but not hCG. It was demonstrated in African catfish that recombinant $\mathrm{LH}$, but not hCG, activated both FSH-R and LH-R (Bogerd et al. 2001). In addition, even though hCG activated FSH-R in channel catfish (Kumar et al. 2001b), the concentration for FSH-R activation was over $100 \mathrm{IU} / \mathrm{ml}(\sim 10 \mathrm{~g} / \mathrm{ml})$ that is much higher than the effective concentration of Ip rec-LH, $50 \mathrm{ng} / \mathrm{ml}$ total protein of the IMAC-purified rec-LH (an estimated $7 \cdot 5 \mathrm{ng} / \mathrm{ml} r e c-\mathrm{LH}$ ). Therefore, at least, the affinity and specificity of the rec-LH to the GtH-Rs appear to be different from that of hCG. This finding suggests that studies using hCG with fish models may have yielded inappropriate conclusions. This conclusion is significant because hCG is often used as a 'standard' LH in fish systems.

In contrast to rec-LH, treatment with rec-FSH was essentially incapable of modulating transcriptional activity of these genes (with the exception of $3 \beta-H S D$ ) in post-vitellogenic follicles. Since P450arom expression was stimulated with rec-FSH in follicles in the vitellogenic growth stage (Fig. 5), it is clear that the FSH-mediated regulation of P450arom (and likely the other genes as well) is dependent on the developmental stages of the ovarian follicles. It has been demonstrated in adult catfish that the FSH-R expression is elevated in association with the onset of ovarian recrudescence and decreases prior to spawning (Kumar et al. 2001b). Therefore, the stage-dependent modulation of P450arom gene by FSH may be partially due to the abundance of the receptor.

In summary, a method was developed to abundantly produce bioactive recombinant channel catfish FSH and LH that has been engineered to facilitate purification. Presumably, the same strategy can be used with other species to generate wild-type GtHs (for endocrine studies, aquacultural manipulations, or antibody production) and GtHs with site-specific mutations (for structure-function studies). As with many species of fish, isolation of native FSH from pituitaries has been unsuccessful, therefore this methodology may be the sole mechanism to generate useful quantities of this hormone.
Furthermore, the ability to generate rec-LH and rec-FSH for fish species in which these GtHs are not available will enable precise examinations of the mechanisms by which target tissues respond and dissect the functional duality of the FSH and $\mathrm{LH}$ system. The function and interaction of GtHs in more fish models can finally be examined with species-specific reagents.

\section{Acknowledgements}

We would like to thank Dr Yonathan Zohar of the Center of Marine Biotechnology, University of Maryland Biotechnology Institute for the kind gift of anti-striped bass $\beta$-LH antisera, and Ms Wytske van Dijk of the University of Utrecht for excellent technical assistance. This work was supported by a grant from the US Department of Agriculture to JMT (00-35203-9105) and by a grant from the Norwegian Research Council to RWS (grant \# 159645/S40). The authors declare that there is no conflict of interest that would prejudice the impartiality of this scientific work.

\section{References}

Aizen J, Kasuto H, Golan M, Zakay H \& Levavi-Sivan B 2007 Tilapia folliclestimulating hormone (FSH): immunochemistry, stimulation by gonadotropin-releasing hormone, and effect of biologically active recombinant FSH on steroid secretion. Biology of Reproduction 76 692-700.

Amano J \& Kobata A 1993 Direct interaction of the sialic acid residue of human lutropin and chorionic gonadotropin with target cell is necessary for the full expression of their hormonal action. Archives of Biochemistry and Biophysics 305 619-621.

Ben-Menahem D, Kudo M, Pixely MR, Sato A, Suganuma N, Perlas E, Hsueh AJW \& Boime I 1997 The biologic action of single-chain chorioginadotropin is not dependent on the individual disulfide bonds of the $\beta$ subunit. Journal of Biological Chemistry 272 6827-6830.

Bogerd J, Blomenrohr M, Andersson E, van der Putten HH, Tensen CP, Vischer HF, Granneman JC, Jansen-Dommerholt C, Goos HJ \& Schutz RW 2001 Discrepancy between molecular structure and ligand selectivity of a testicular follicular-stimulating hormone receptor of the African catfish (Clarias gariepinus). Biology of Reproduction 64 1633-1643.

Campbell B, Dickey JT \& Swanson P 2003 Endocrine changes during onset of puberty in male spring chinook salmon, oncorhynchus tshawytscha. Biology of Reproduction $692109-2117$.

Copeland PA \& Thomas P 1993 Isolation of gonadotropin subunits and evidence for two distinct gonadotropins in Atlantic croaker (Micropogonias undulatus). General and Comparative Endocrinology 91 115-125.

Cui M, Li W, Liu W, Yang K, Pang Y \& Haoran L 2007 Production of recombinant orange-spotted grouper (Epinephelus coioides) luteinizing hormone in insect cells by the baculovirus expression system and its biological effect. Biology of Reproduction 76 74-84.

Garcia-Hernandez MP, Koide Y, Diaz MY \& Kawauchi H 1997 Isolation and characterization of two distinct gonadotropins from the pituitary gland of Mediterranean yellowtail, seriola dumerilo (Risso, 1810). General and Comparative Endocrinology 196 389-399.

Gharib SD, Wierman ME, Shupnik MA \& Chin WW 1990 Molecular biology of the pituitary gonadotropins. Endocrine Reviews 11 177-199.

Hakola H, Boogaart PVD, Mulders J, de Leeuw R, Schoonen W, Heyst JV, Swolfs A, Casteren JV, Huhtaniemi H \& Kloosterboer H 1996 Recombinant rat follicle-stimulating hormone; production by Chinese hamster ovary cells, purification and functional characterization. Molecular and cellular Endocrinology 127 59-69. 
Hakola H, Boogaart PVD, Mulders J, de Leeuw R, Schoonen W, Heyst JV, Swolfs A, Casteren JV, Huhtaniemi H \& Kloosterboer H 1997 Recombinant rat luteinizing hormone; production by Chinese hamster ovary cells, purification and functional characterization. Molecular and Cellular Endocrinology 128 47-56.

Itoh H, Zusuki K \& Kawauchi H 1988 The complete amino acid sequences of $\beta$ subunits of two distinct chum salmon GTHs. General and Comparative Endocrinology 71 438-451.

Kamei H, Ohira T, Yoshiura Y, Uchida N, Nagasawa H \& Aida K 2003 Expression of a biologically active recombinant follicle stimulating hormone of Japanese Eel Anguilla japonica using methylotropic yeast, Pichia pastoris. General and Comparative Endocrinology 134 244-254.

Ko H, Park W, Kim DJ, Kobayashi M \& Sohn YC 2007 Biological activities of recombinant Manchurian trout FSH and LH: their receptor specificity, steroidogenic and vitellogenic potencies. Journal of Molecular Endocrinology 38 99-111.

Koide Y, Itoh H \& Kawauchi H 1993 Isolation and characterization of two distinct gonadotropins, GTHI and GTHII, from bonito (Katsuwonus plelamis) pituitary glands. Journal of Peptide Research 41 52-65.

Van Der Kraak G, Suzuki K, Peter RE, Itoh H \& Kawauchi H 1992 Properties of common carp gonadotropin I and gonadotropin II. General and Comparative Endocrinology 85 217-229.

Krishnamurthy H, Kats R, Danilovich N, Javeshghani D \& Sairam MR 2001 Intercellular communication between Sertoli cells and Leydig cells in the absence of follicle-stimulating hormone-receptor signaling. Biology of Reproduction 65 1201-1207.

Kumar RS \& Trant JM 2004 Hypophyseal gene expression profiles of FSH- $\beta$, LH- $\beta$, and glycoprotein hormone- $\alpha$ subunits in Ictalurus punctatus throughout a reproductive cycle. General and Comparative Endocrinology 136 82-89.

Kumar SR, Ijiri S \& Trant JM 2000 Changes in the expression of genes encoding steroidogenic enzymes in the channel catfish (Ictalurus punctatus) ovary throughout a reproductive cycle. Biology of Reproduction 63 1676-1682.

Kumar SR, Ijiri S \& Trant JM 2001a Molecular biology of channel catfish gonadotropin receptors: 1 . Cloning of functional luteinizing hormone receptor and preovulatory induction of gene expression. Biology of reproduction 64 1010-1018.

Kumar SR, Ijiri S \& Trant JM $2001 b$ Molecular biology of channel catfish gonadotropin receptors: 2. Complementary DNA Cloning, functional expression, and seasonal gene expression of follicle-stimulating hormone receptor. Biology of Reproduction $\mathbf{6 5} 710-717$.

Kusakabe M, Nakamura I, Evans J, Swanson P \& Young G 2006 Changes in mRNAs encoding steroidogenic acute regulatory protein, steroidogenic enzymes and receptors for gonadotropins during spermatogenesis in rainbow trout testes. Journal of Endocrinology 189 541-554.

Lathi RB \& Milki AA 2001 Recombinant gonadotropins. Current Women's Health Reports 1 157-163.

Liu Z, Li P, Argue BJ \& Dunham RA 1997 Gonadotropin $\boldsymbol{\alpha}$-subunit glycoprotein from channel catfish (Ictalurus punctatus) and its expression during hormone-induced ovulation. Molecular Marine Biology and Biotechnology 6 217-227.

Mananos EL, Swanson P, Stubblefield J \& Zohar Y 1997 Purification of gonadotropin II from a teleost fish, the hybrid striped bass, and development of a specific enzyme-linked immunosorbent assay. General and Comparative Endocrinology 108 209-222.

Mountford PS, Brandon MR \& Adams TE 1994 Expression and characterization of biologically active ovine FSH from mammalian cell line. Journal of Molecular Endocrinology 12 71-83.
Pierce JG \& Parsons TF 1981 Glycoprotein hormones: structure and function. Annual review of Biochemistry 50 465-495.

Planas JV \& Swanson P 1995 Maturation-associated changes in the response of the salmon testis to the steroidogenic actions of gonadotropins (GTH I and GTH II) in vitro. Biology of Reproduction 52 697-704.

Schulz RW, Renes IB, Zandbergen MA, van Dijk W, Peute J \& Goos HJTh 1995 Pubertal development of male African catfish (Clarias gariepinus), pituitary ultrastructure and responsiveness to GnRH. Biol Reprod 53 907917.

Schulz RW, Lubberink K, Zandbergen MA, Janssen-Dommerholt C, Peute J \& Goos HJTh 1996 Testicular responsiveness to gonadotropic hormone in vitro and Leydig and Sertoli cell ultrastructure during pubertal development of male African catfish (Clarias gariepinus). Fish Physiology and Biochemistry 15 243-254.

Schulz RW, Vischer HF, Cavaco JE, Santos EM, Tyler CR, Goos HJ \& Bogerd J 2001 Gonadotropins, their receptors, and the regulation of testicular functions in fish. Comparative Biochemistry and Physiology. Part B, Biochemistry and Molecular Biology 129 407-417.

Slater CH, Schreck CB \& Swanson P 1994 Plasma profiles of the sex steroids and gonadotropins in maturing female spring Chinook salmon (Oncorynchus tshawytscha). Comparative Biochemistry and Physiology 109 165-175.

So WK, Kwok HF \& Ge W 2005 Zebrafish gonadotropins and their receptors: II. Cloning and characterization of zebrafish follicle-stimulating hormone and luteinizing hormone subunits-their spatial-temporal expression patterns and receptor specificity. Biology of Reproduction 72 1382-1396.

Suzuki K, Kawauci H \& Nagahama Y 1988 Isolation and characterization of two distinct gonadotropins from chum salmon pituitary glands. General and Comparative Endocrinology $\mathbf{7 1}$ 292-301.

Swanson P \& Dittman A 1997 Pituitary gonadotropins and their receptors in fish. Proceedings of the XIII International Congress of Comparative Endocrinology, Yohama, Japan, pp. 841-846.

Swanson P, Suzuki K, Kawauchi H \& Dickhoff WW 1991 Isolation and characterization of two coho salmon gonadotropins, GTH I and GTH II. Biology of reproduction 44 29-38.

Szkudlinski MW, The GN, Grossman M, Tropea JE \& Weintraub BD 1996 Engineering human glycoprotein hormone superactive analogues. Nature Biotechnology 14 1257-1263.

Tanaka H, Kagawa H, Okuzawa K \& Hirose K 1993 Purification of gonadotropins (PmGTH I and II) from the red seabream (Pagurus major) and development of a homologous radioimmunoasay for PmGtH II. Fish Physiology and Biochemistry 11 409-418.

Vermeulen GJ, Lambert JGD, Lenczowski MJP \& Goos HJTh 1993 Steroid hormone secretion by testicular tissue from African catfish, Clarias gariepinus, in primary culture: identification and quantification by gas chromatography-mass spectrometry. Fish Physiology and Biochemistry 12 21-30.

Vischer HF, Granneman JCM, Linskens MHK, Schulz RW \& Bogerd J 2003 Both recombinant African catfish LH and FSH are able to activate the African catfish FSH receptor. Journal of Molecular Endocrinology 31 $133-140$

Received in final form 30 May 2007

Accepted 4 June 2007

Made available online as an Accepted Preprint 8 June 2007 